Dear Author,

Please, note that changes made to the HTML content will be added to the article before publication, but are not reflected in this PDF.

Note also that this file should not be used for submitting corrections. 


\title{
Epigenetic modulation, stress and plasticity in susceptibility of the snail host, Biomphalaria glabrata, to Schistosoma mansoni infection
}

\author{
Matty Knight ${ }^{\mathrm{a}, \mathrm{b}, *}$, Wannaporn Ittiprasert ${ }^{\mathrm{a}}$, Halime D. Arican-Goktas ${ }^{\mathrm{c}}$, Joanna M. Bridger ${ }^{\mathrm{c}}$ \\ ${ }^{a}$ Department of Microbiology, Immunology E Tropical Medicine, and Research Center for Neglected Diseases of Poverty, School of Medicine E Health Sciences, The George \\ Washington University, Ross Hall, 2300 I (Eye) Street, NW, Washington, DC 20037, USA \\ ${ }^{\mathrm{b}}$ Division of Science \& Mathematics, University of the District of Columbia, 4200 Connecticut Avenue, NW, Washington, DC 20008, USA \\ ${ }^{\mathrm{c}}$ Genome Engineering and Maintenance Network, Institute of Environmental, Health and Societies, Brunel University London, Uxbridge, UK
}

\section{A R T I C L E I N F O}

\section{Article history:}

Received 15 January 2016

Received in revised form 14 March 2016

Accepted 15 March 2016

Available online $\mathrm{xxxx}$

\section{Keywords:}

Biomphalaria glabrata

Snail host

Schistosoma mansoni

Platyhelminth parasite

Susceptibility

Spatio-epigenetics

Hypomethylation

Stress

\begin{abstract}
A B S T R A C T
Blood flukes are the causative agent of schistosomiasis - a major neglected tropical disease that remains endemic in numerous countries of the tropics and sub-tropics. During the past decade, a concerted effort has been made to control the spread of schistosomiasis, using a drug intervention program aimed at curtailing transmission. These efforts notwithstanding, schistosomiasis has re-emerged in southern Europe, raising concerns that global warming could contribute to the spread of this disease to higher latitude countries where transmission presently does not take place. Vaccines against schistosomiasis are not currently available and reducing transmission by drug intervention programs alone does not prevent reinfection in treated populations. These challenges have spurred awareness that new interventions to control schistosomiasis are needed, especially since the World Health Organization hopes to eradicate the disease by 2025 . For one of the major species of human schistosomes, Schistosoma mansoni, the causative agent of hepatointestinal schistosomiasis in Africa and the Western Hemisphere, freshwater snails of the genus Biomphalaria serve as the obligate intermediate host of this parasite. To determine mechanisms that underlie parasitism by S. mansoni of Biomphalaria glabrata, which might be manipulated to block the development of intramolluscan larval stages of the parasite, we focused effort on the impact of schistosome infection on the epigenome of the snail. Results to date reveal a complex relationship, manifested by the ability of the schistosome to manipulate the snail genome, including the expression of specific genes. Notably, the parasite subverts the stress response of the host to ensure productive parasitism. Indeed, in isolates of B. glabrata native to central and South America, susceptible to infection with S. mansoni, the heat shock protein 70 (Bg-HSP70) gene of this snail is rapidly relocated in the nucleus and transcribed to express HSP70. Concurrently, hypomethylation of the CpG sites, within the Bg-HSP70 intergenic DNA region, proceeds by conveying epigenetic and spatio-epigenetic mechanisms in temporal concordance. It is notable that this is only the second example reported where a pathogen has been shown to control host cell spatio-epigenetics for its own advantage. Nonetheless, the remarkable mechanisms through which genes become activated i.e. DNA and chromatin remodeling and relocation to a nuclear compartment conducive to gene expression may represent novel intervention targets.
\end{abstract}

(c) 2016 Published by Elsevier Ltd. on behalf of Australian Society for Parasitology Inc.

Medicine, and Research Center for Neglected Diseases of Poverty, School of Medicine \& Health Sciences, The George Washington University, Ross Hall, 2300 I (Eye) Street, NW, Washington, DC 20037, USA.

E-mail address: matty_knight@gwu.edu (M. Knight). schistosomiasis has re-emerged in Europe, raising concerns that global warming may be contributing to the spread of the disease 
into countries hitherto beyond the present endemic range (Boissier et al., 2015). The World Health Organization (WHO) has projected the year 2025 for the global eradication of schistosomiasis, http:// www.who.int/tdr/news/2016/key_challenges_identified_elim_ ntd/en/. However, without an effective vaccine, no new drugs and poor access to clean water and sanitation in endemic areas, there is a growing awareness that alternative tools to control schistosomiasis, based on blocking parasite development in the snail host, have to be explored (King and Bertsch, 2015). There is an ongoing debate to return to the 'gold-standard' method of using molluscicides to reduce snail populations (King and Bertsch, 2015). Other, more ecotors, and bacterial pathogens, to control snail populations in contaminated freshwater have clear utility, at least in some regions (Duval et al., 2015; Sokolow et al., 2015). Indeed, the concept of biologically based control was proposed more than 60 years ago (Hubendick, 1958). As proof of principle, incompatible snails have been used in endemic areas to reduce transmission of schistosomiasis (Pointier, 1993; Marques et al., 2014).

The life cycle of schistosomes is complex, with snails serving as the intermediate host and humans as the definitive host. Whereas in most cases not every snail that encounters a parasite becomes infected, the human host, on the other hand, is always susceptible to infection once the infective cercaria (released from an infected snail) penetrates the human skin. This difference in the dynamics of infection outcome between the snail and human host is thought to reflect that the snail, rather than the human host, shapes the genetic make-up of the schistosome. Co-evolution of this snail/parasite interplay, resulting either in successful parasite development in a susceptible/compatible snail, but destruction in a resistant/ incompatible one, is enigmatic and worthy of deeper investigation.

During the past two decades, however, more studies on the snail/schistosome relationship have been undertaken (Knight et al., 2014; Mutuku et al., 2014; Yoshino et al., 2014). These studies showed that several factors play a role in what determines the outcome of the snail/schistosome interaction. The focus of our work in this area has been to begin to examine the role of epigenetics in modulating snail host susceptibility to schistosome infection (Knight et al., 2014). Epigenetic mechanisms in a host-parasite relationship generate plasticity that drives adaptability/coevolution between the host and parasite. Epigenetics is defined as covalent modification (methylation and acetylation, and others) of the chromatin that regulates gene expression without any alteration in underlying DNA sequence. These changes confer an inheritable trait and in a host-pathogen interaction provides a selective pressure that shapes parasite survival versus destruction in the host. An instructive example, in the snail host and schistosome interaction, is the epigenetic control that has been shown to link snail compatibility and incompatibility to the transcription of diverse parasite mucin ( $\mathrm{SmPoMuC}$ ) genes for productive parasitism (Perrin et al., 2013). A recent study has also shown the epigenetic control of transcription regulation in the infective form of the parasite, the cercaria (Roquis et al., 2015). The significance of epigenetics in regulating gene expression in the host-pathogen interaction of invertebrates is understudied. However, a recent workshop showed there exists a growing interest in elucidating the role of epigenetic regulation and phenotypic plasticity in marine and fresh water molluscs (http://ihpe.univ-perp.fr/2-fevrierworkshop-on-mollusk-epigenetic/).

A genomic response to an external stimulus such as an infection requires signaling through to the nucleus and the genome via the cytoplasm, through the nuclear membrane, into the nucleus, where the response is transmitted to the chromatin. The nucleus is a highly organized organelle with numerous, diverse structures that interact with and influence the genome. These structures include the nuclear lamina, nucleoli and other nuclear bodies. We have logically acceptable approaches involving prawns and other preda- shown that a number of these exist in Biomphalaria glabrata, using antibodies that recognize the human versions of antigens within these structures (Knight et al., 2014). These structures look remarkably similar to nuclear structures found in human cells that we were hoping to identify in the snail cells (Knight et al., 2014). We also revealed that the mollusk $B$. glabrata has chromosome territories (Odoemelam et al., 2009) very similar in shape and organization to more complex species such as human, pig and mouse (Odoemelam et al., 2009). Further studies with B. glabrata interphase chromosome territories demonstrated that they did not have a Rabl-type configuration in the nucleus but a radial distribution with individual chromosomes sitting in non-random locations, also in common with higher eukaryotes. Chromosomes have been found to be comparatively static at interphase (Chubb et al., 2002), not showing much movement after the early $\mathrm{G} 1$ phase due to becoming tethered to nuclear structures. This territorial organization of chromosomes leads to spaces between chromosomes into which RNA is transcribed (Lampel et al., 1997; Bridger et al., 2005) and genes can move within (Kosak and Groudine, 2004a,b), as they come out on chromatin loops away from the main body of the chromosome territory, to be activated or silenced. Having chromosomes and genes spatially organized in such a way requires signaling, chromatin modeling, protein modification and energy, and thus spatial organization and positioning must convey an advantage to the organism. Furthermore, this specific positioning of genomic elements to different compartments within interphase nuclei gives a further level of regulation and control over the genome, over and above linear DNA sequence and epigenetics via chromatin remodeling, by bringing the genome into association with specific nuclear areas and structures that are involved in expression or repression of genes such that the nuclear structure field understand this organization as some type of spatio-epigenetics.

The ability to assess non-random gene positioning in nuclei by a variety of methods is permitting more knowledge concerning how the genome behaves in health and disease but also responds to external stimuli. Interestingly, interphase gene positioning is even being developed as a cancer diagnostic and prognostic tool (Meaburn et al., 2009). It seems that many genes, but not all, move towards the nuclear interior and associate with nuclear structures such as transcription factories, splicing speckles or nuclear bodies, in order to be transcribed. Indeed, in porcine mesenchymal stem cells induced to differentiate into adipocytes, genes activated in the adipogenesis pathway relocate to a new nuclear compartment more interiorly positioned in the cell nuclei (Szczerbal et al., 2009). Interestingly, these activated genes were found out on chromatin loops, and even though they were from different chromosomes they were often co-localized at a single splicing speckle concomitantly with their up-regulation (Szczerbal and Bridger, 2010). Activated genes can also relocate to transcription factories (Sexton et al., 2007). In order for the specific regions of chromatin to be moved, a change in chromatin status through epigenetics is likely necessary, such that the locus becomes remodeled and is subjected to quite rapid directional movement to the new compartment, possibly through nuclear motor activity (Bridger, 2011).

Here we review the Schistosoma mansoni-B. glabrata interaction and the capacity of schistosomes to influence host genome behavior. Through gene position analysis using labeled probes and fluorescence in situ hybridization (FISH) we demonstrated that spatioepigenetics is activated in the snail soon after exposure to the parasite. Schistosomes have the ability to stimulate the expression of snail genes within $2 \mathrm{~h}$ of penetration by the miracidium of the snail. Non-random movement of gene loci occurs within the same time frame as the hypomethylation of the heat shock protein (HSP) 70 locus - a processes that turns on this stress protein at both RNA and protein levels (Arican-Goktas et al., 2014; Knight et al., 2015). Aside from one study of infection with Epstein-Barr virus, which 
induces the movement of chromosome 17 in infected human cells ( $\mathrm{Li}$ et al., 2010), other pathogens have not been reported to orchestrate changes in the host they occupy to alter the host genome behavior in such a profound manner. Unraveling the mechanism(s) behind these novel results should provide opportunities to develop tools that can be utilized to block schistosome transmission in the snail host.

\section{Schistosoma mansoni miracidia induce stress upon early infection of the $B$. glabrata snail host}

Miracidia, the short-lived, free-living stage of the parasite, hatch in freshwater once the eggs in human urine and feces are released in endemic foci such as rivers, lakes and streams. Miracidia infect compatible snail hosts by penetrating soft body parts (headfoot or the tentacles). In laboratory reared B. glabrata infected with S. mansoni that are maintained in the experimental mouse model, Richards and Shade (1987) showed that snail susceptibility was variable but dependent on whether or not the parasite and snail were genetically compatible. Genetic crosses between susceptible (e.g. NMRI strain) and resistant (e.g. BS-90 strain) snails revealed that resistance is a complex trait in juvenile snails but a Mendelian singlegene character in the adult snails (Knight et al., 1999; Ittiprasert et al., 2013). In recent studies we showed that susceptibility in the S. mansoni/B. glabrata relationship can be modulated by whether or not stress-encoding transcripts (e.g. HSP 70, HSP 90) are induced early and significantly within the early phase of miracidia penetrating the snail. Whereas stress genes are induced early in susceptible/compatible snails, up-regulation of these genes fails to occur until later during infection in the resistant snail. Intriguingly, neither irradiated attenuated (Ittiprasert et al., 2009) miracidia nor incompatible heterologous schistosome spp. (Schistosoma haematobium, Schistosoma japonicum) induce an early stress response in the B. glabrata susceptible snail (Adema et al., unpublished data).

\section{Non- lethal heat shock renders the resistant BS-90 snail host susceptible to infection, and geldanamycin treatment of susce- ptible snails before infection renders them non-susceptible}

To further investigate the role of stress in B. glabrata susceptibility to $S$. mansoni, the resistant BS-90 snail was subjected to mild heat shock $\left(32^{\circ} \mathrm{C}\right)$ to induce HSP 70 and HSP 90 prior to infection.
Surprisingly, resistant snails treated in this manner were found to shed cercariae at 4 weeks post-exposure while the susceptible NMRI snail treated with geldanamycin, an HSP 90 inhibitor, before infection were rendered non-susceptible (Fig. 1) (Ittiprasert and Knight, 2012). Expression of HSP70 protein occurs in susceptible but not resistant adult and juvenile snails exposed to wild-type but not to irradiated miracidia (Knight et al., 2015). Importantly, progeny as early as the first filial generation of resistant BS-90 snails maintained at $32{ }^{\circ} \mathrm{C}$ become susceptible when infected and kept at $25^{\circ} \mathrm{C}$ - a temperature at which they are normally resistant to the parasite.

Clearly, these findings revealed that early stress induction (within $2 \mathrm{~h}$ ) after miracidia penetration of the snail is an important step that enables the parasite to establish itself in the snail host, although we do not yet understand the signaling pathways involved in this unprecedented rapid upregulation of stress in the early parasite-infected susceptible snail. Until we identify which snail proteins interact with these schistosome-induced heat shock proteins it will be difficult to determine how this early stress induction directly or indirectly affects parasite infectivity in the susceptible/compatible snail host. To begin to identify candidate proteins associated with stress in the early schistosome-infected snail from a working hypothesis that these proteins directly facilitate early stage parasite development/differentiation in the snail host, we are comparing transcriptomes between BS-90 snails exposed to parasites for $2 \mathrm{~h}$ cultured either at $25^{\circ} \mathrm{C}$ (resistant) or at the permissive temperature $\left(32^{\circ} \mathrm{C}\right)$ by using an RNA sequencing (RNAseq) approach (unpublished data).

\section{Spatio-epigenetics and early modulation of transcription occurs in the schistosome-infected B. glabrata snail host}

Strikingly, we have shown that B. glabrata genes that are upregulated after an infection, such as HSP70, actin and ferritin, relocate in the cell nuclei from a non-random position to a new non-random site within interphase nuclei. This spatial reorganization of specific regions of the snail genome has been revealed in embryonic $B$. glabrata tissue culture cells (Bge) co-cultured with parasite (Knight et al., 2011) and in intact snails (from somatic ovotestis nuclei) undergoing infection with schistosomes (Arican-Goktas et al., 2014). These studies revealed that a gamma irradiated, and hence

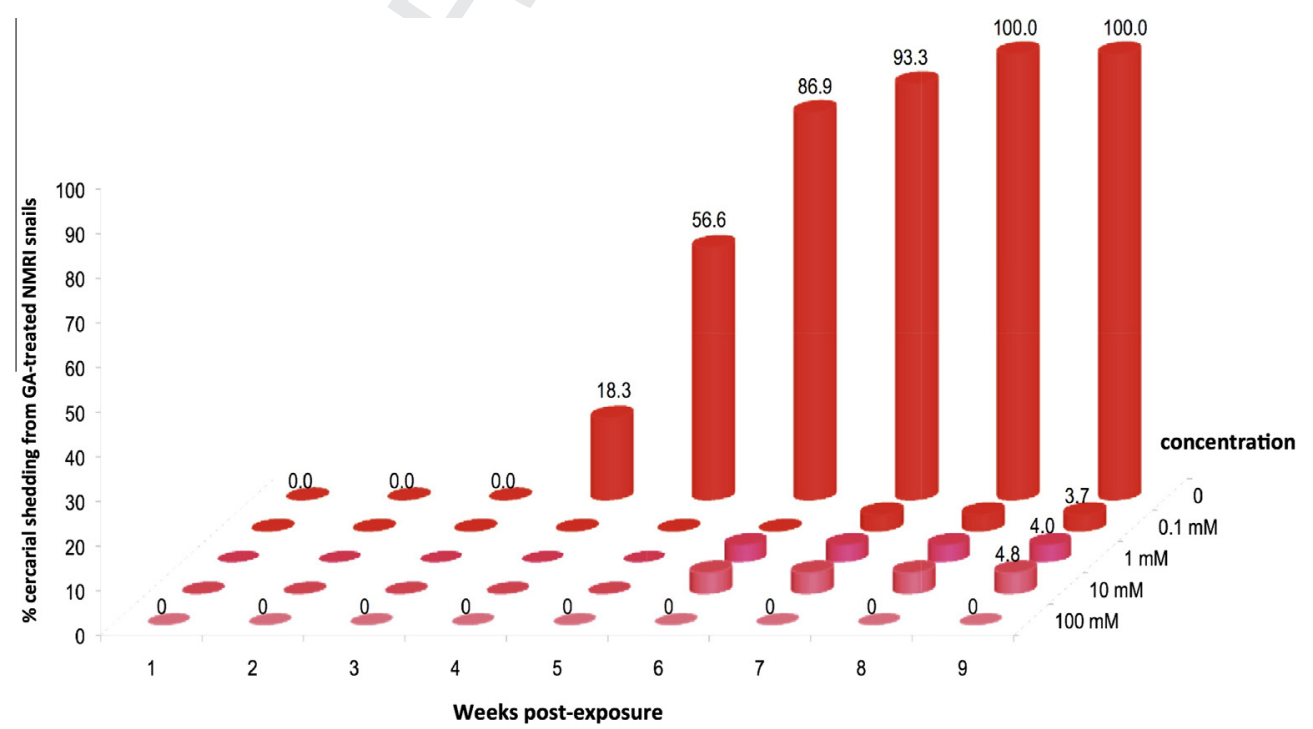

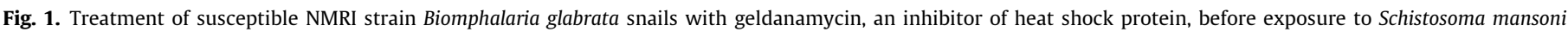

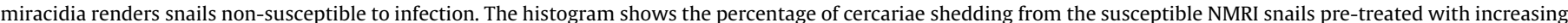

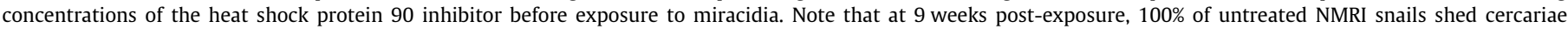
compared with snails treated with $100 \mathrm{mM}$ geldanamycin that failed to shed cercariae. Modified with permission from Fig. $6 \mathrm{~B}$ of Ittiprasert and Knight, 2012. 


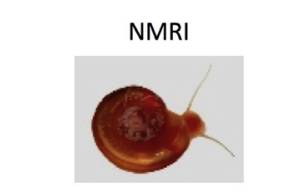

+ S. mansoni live miracidia
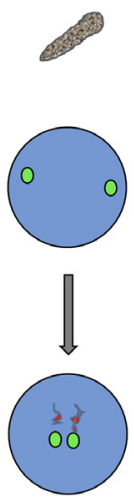

NMRI

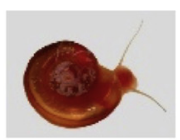

+ S. mansoni attenuated miracidia
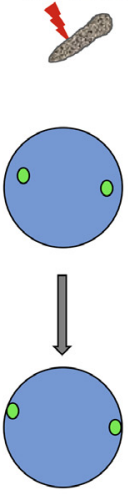

BS-90

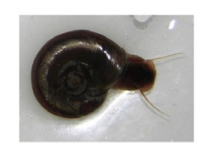

+S. mansoni live miracidia
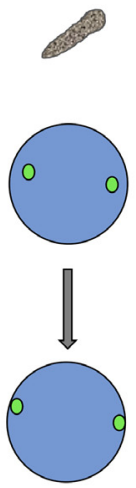

BS-90

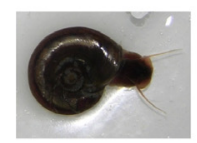

+ S. mansoni attenuated

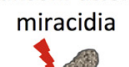

1.
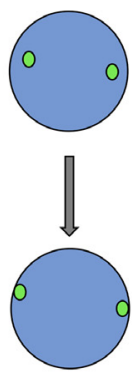

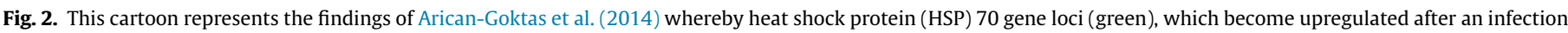

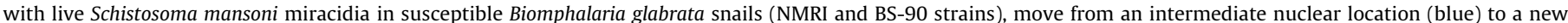

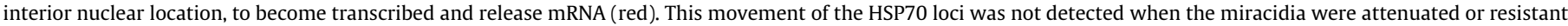

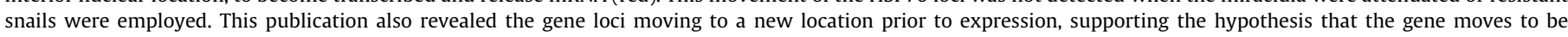
transcribed not the other way around.

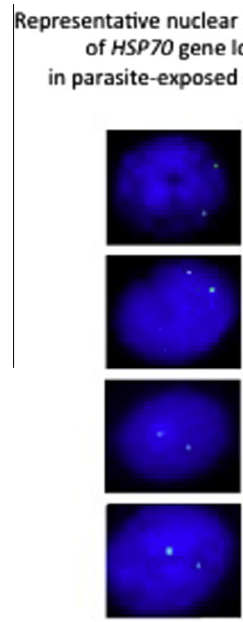

Correlation of HSP7O gene loci position with up-regulation of expression

$30 \mathrm{~min}$

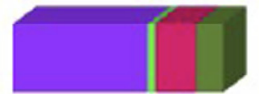

$2 \mathrm{~h}$

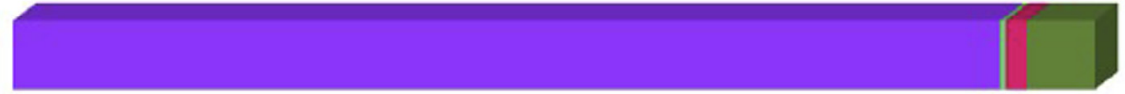

$5 \mathrm{~h}$

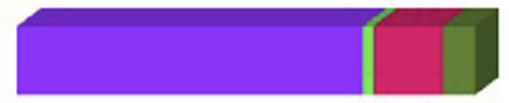

0

5

10

15

20

25

30

mSSP70 exp Susp Snail wt Mira =HSP70 exp Susp Snail Att Mira =HSP70 exp Rest Snail wt Mira $\quad$ mSP70 exp Rest Snail Att Mira

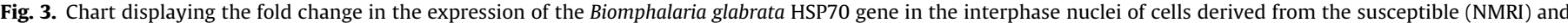

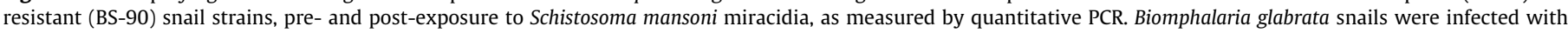

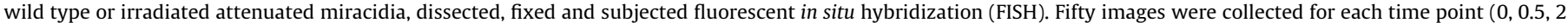

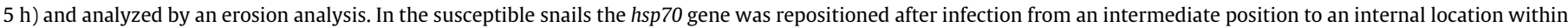

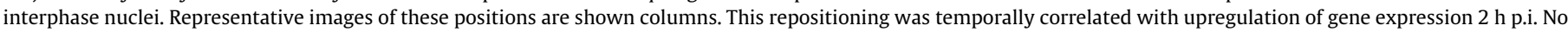

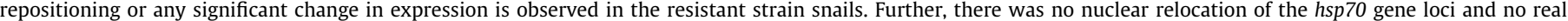
HSP70 expression was detected by quantitative PCR when the two snail lines were infected with irradiated miracidia.

attenuated, parasite fails to elicit the same spatial relocation of these gene loci both in vitro and in vivo (Fig. 2). Indeed, the actin gene has been the most interesting of the genes moving, as it reveals for the first time that gene loci move $\sim 30$ min before transcription is detected by quantitative PCR. This is an important aspect of genome behavior where the hypothesis that gene loci move to a new area within the nucleus to be expressed has yet to be substantially proven. Our studies have provided the first evidence that a gene moves prior to activation (Knight et al. 2014) (Fig. 2). Our data also revealed that the parasite is orchestrating the behavior of specific genes, specifically HSP 70, for its own advantage, since the movement and expression of HSP 70 gene loci is not seen in snails resistant to the schistosome infection (Fig. 3). We have yet to show how the parasite elicits such changes in the host genome but we have some preliminary evidence that nuclear motor proteins are indeed involved in the relocation of gene loci. 


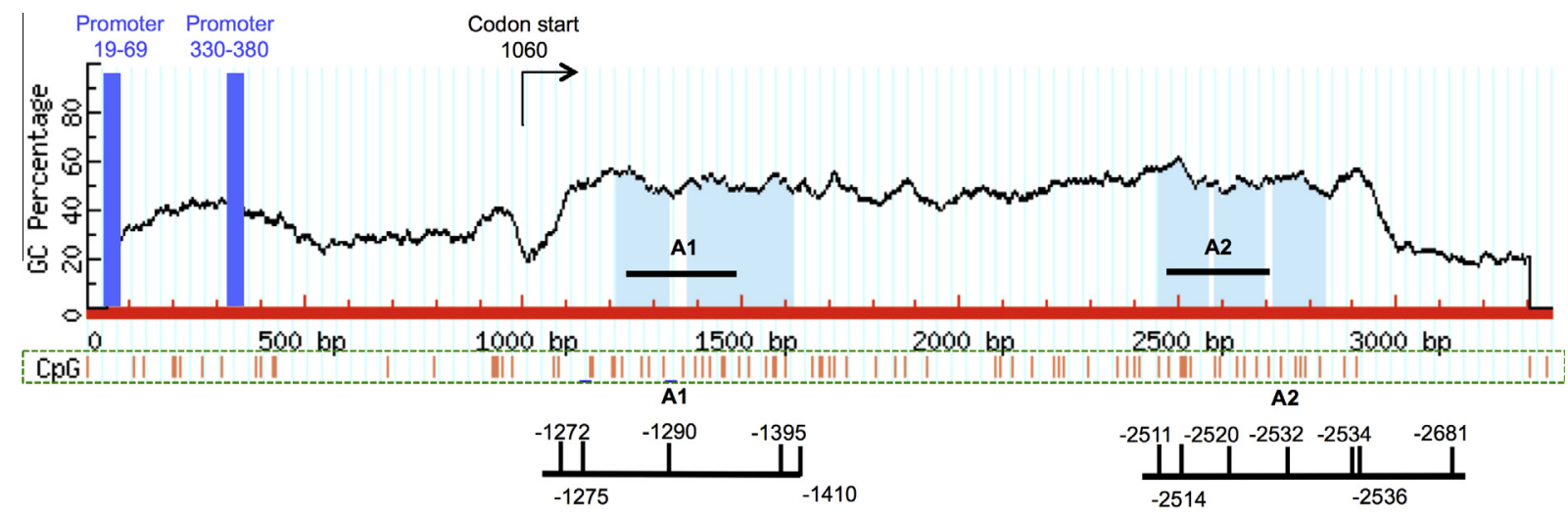

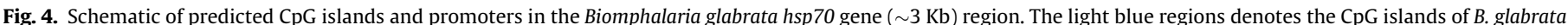

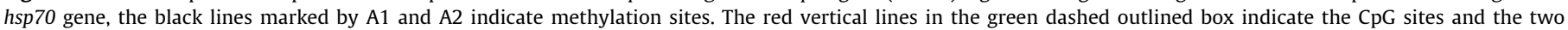
promoters (locations 19-69 and 330-380) that did not contain CpG sites. Reproduced with permission from Fig. 1A of Ittiprasert et al., 2015.

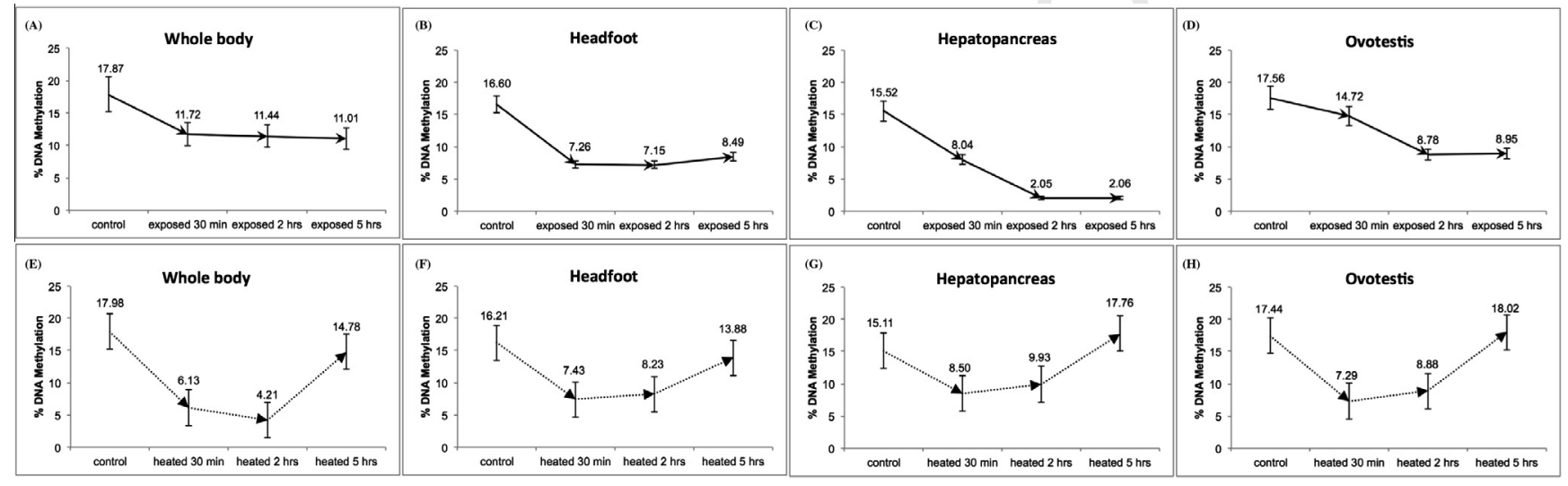

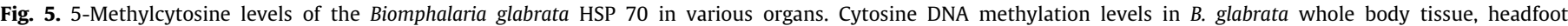

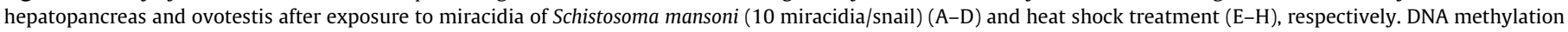

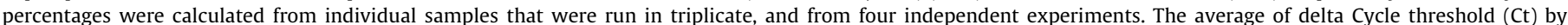

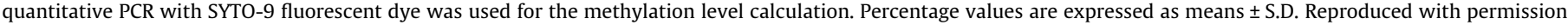
from Fig. 2 of Ittiprasert et al., 2015.

\section{Hypomethylation of CpG islands of the HSP 70 locus negatively correlates with upregulation of the transcript in susceptible snail organs after schistosome infection}

To determine more closely whether epigenetic modifications at the HSP 70 locus influence B. glabrata susceptibility to S. mansoni, the methylation of cytosine residues, specifically CpG dinucleotides in the HSP 70 region (Fig. 4) was evaluated in the NMRI strain susceptible snail undergoing stress from either heat shock (abiotic stress at $32{ }^{\circ} \mathrm{C}$ ) or $\mathrm{S}$. mansoni infection (biotic stress) (Ittiprasert et al., 2015). Methylation of CpG residues in the genome has been shown to modify gene expression without any underlying change to the DNA sequence. Two percent of the DNA of B. glabrata may be methylated (Fneich et al., 2013). Thus, to quantify differences in DNA methylation between normal and stressed snails, levels of DNA methylation were measured in snail tissues (whole body, headfoot, hepatopancreas and ovotestis), following infection or heat shock. Both stressors led to decreased levels of methylation of HSP 70, in a time-dependent manner, concurrently with increases in transcription of HSP 70 (Fig. 5). Temporal hypomethylation of the locus differed, depending on whether the snail was responding to abiotic or biotic stress, and was also more dramatic and longer lasting in the DNA from the hepatopancreas of infected snails, reflecting the upregulation of transcription of HSP 70 in this snail organ. These results remain to be further investigated by more profiling of the methylome of the susceptible snail while responding to various stressful conditions. To date, we have also shown that as has previously been reported for other invertebrates, DNA methylation of the HSP 70 locus occurs within the gene body but not the promotor region (Gavery and Roberts, 2013). Promotor region DNA methylation in a mollusk has, however, been recently reported (Saint-Carlier and Riviere, 2015).

\section{Closing remarks}

The role of epigenetics and susceptibility of the snail host to schistosome infection is a new frontier in the search to uncover mechanisms of parasitism that can be blocked to disrupt transmission of this tropical disease. To date we have shown that the incoming parasite has the ability to regulate expression of stress genes in the snail host via spatio-epigenetics and change in DNA methylation patterns in snail organs. Importantly, these epigenetic modulations take place within a short time frame post-schistosome exposure of the snail host and underscores a phenotype that either leads to resistance or susceptibility to infection. The factor(s) released from the parasite excretory secretory products (ESPs) signaling via the stress pathway to reprogram chromatin in order to modify transcriptional regulation in the snail host genome for its own gain remains to be identified. The proteome of ESPs from 
S. mansoni developmentally transforming miracidia has been reported (Wu et al., 2009), facilitating comparison of ESPs with products released from irradiated attenuated miracidia, so we can search for candidate proteins present only in wild type miracidia. With the recent release of a draft genome of $B$. glabrata (Adema et al., unpublished data) and the advent of better genome editing tools such as the CRISPR-Cas9 system (Mali et al., 2013; Pennisi, 2013) that also is active in mollusks (Perry and Henry, 2015), we can envision that a knock-out snail deplete of heat shock transcription factor can be utilized to further investigate the role of early stress, epigenetic control and plasticity in snail susceptibility in the B. glabrata/S. mansoni host/pathogen model system.

\section{Acknowledgements}

We thank Drs. Victoria Mann and Paul Brindley for comments on the manuscript. We acknowledge support for research findings reviewed here from National Institutes of Health- National Institute of Allergy and Infectious Diseases, USA R01AI63480 (MK), The Clement B.T Knight Cancer Foundation, USA and the Biomedical Research Institute, Rockville, MD, USA.

\section{References}

Arican-Goktas, H.D., Ittiprasert, W., Bridger, J.M., Knight, M., 2014. Differential spatial repositioning of activated genes in Biomphalaria glabrata snails infected with Schistosoma mansoni. PLoS Negl. Trop. Dis. 8 e3013.

Boissier, J., Mone, H., Mitta, G., Bargues, M.D., Molyneux, D., Mas-Coma, S., 2015. Schistosomiasis reaches Europe. Lancet Infect. Dis. 15, 757-758.

Bonds, J.A., 2012. Ultra-low-volume space sprays in mosquito control: a critical review. Med. Vet. Entomol. 26, 121-130.

Bridger, J.M., Kalla, C., Wodrich, H., Weitz, S., King, J.A., Khazaie, K., Krausslich, H.G., Lichter, P., 2005. Nuclear RNAs confined to a reticular compartment between chromosome territories. Exp. Cell Res. 302, 180-193.

Chubb, J.R., Boyle, S., Perry, P., Bickmore, W.A., 2002. Chromatin motion is constrained by association with nuclear compartments in human cells. Curr. Biol. 12, 439-445.

Colley, D.G., 2014. Morbidity control of schistosomiasis by mass drug administration: how can we do it best and what will it take to move on to elimination? Trop. Med. Health 42, 25-32.

Colley, D.G., Secor, W.E., 2014. Immunology of human schistosomiasis. Parasite Immunol. 36, 347-357.

Duval, D., Galinier, R., Mouahid, G., Toulza, E., Allienne, J.F., Portela, J., Calvayrac, C., Rognon, A., Arancibia, N., Mitta, G., Théron, A., Gourbal, B., 2015. A novel bacterial pathogen of Biomphalaria glabrata: a potential weapon for schistosomiasis control? PLoS Negl. Trop. Dis. 9 e0003489.

Fneich, S., Dheilly, N., Adema, C., Rognon, A., Reichelt, M., Bulla, J., Grunau, C., Cosseau, C., 2013. 5-methyl-cytosine and 5-hydroxy-methyl-cytosine in the genome of Biomphalaria glabrata, a snail intermediate host of Schistosoma mansoni. Parasites Vectors 6, 167.

Gavery, M.R., Roberts, S.B., 2013. Predominant intragenic methylation is associated with gene expression characteristics in a bivalve mollusc. Peer] 1 e215.

Hotez, P.J., Brindley, P.J., Bethony, J.M., King, C.H., Pearce, E.J., Jacobson, J., 2008. Helminth infections: the great neglected tropical diseases. J. Clin. Invest. 118, 1311-1321.

Hubendick, B., 1958. A possible method of schistosome-vector control by competition between resistant and susceptible strains. Bull. World Health Organ. 18, 1113-1116.

Ittiprasert, W., Knight, M., 2012. Reversing the resistance phenotype of the Biomphalaria glabrata snail host Schistosoma mansoni infection by temperature modulation. PLoS Pathog. 8 e1002677.

Ittiprasert, W., Miler, A., Knight, M., Tucker, M., Hsieh, M.H., 2015. Evaluation of cytosine DNA methylation of the Biomphalaria glabrata at heat shock protein 70 locus after biological and physiological stresses. J. Parasitol. Vector Biol. 7, 182193.

Ittiprasert, W., Miller, A., Su, X.Z., Mu, J., Bhusudsawang, G., Ukoskit, K., Knight, M., 2013. Identification and characterisation of functional expressed sequence tagsderived simple sequence repeat (eSSR) markers for genetic linkage mapping of Schistosoma mansoni juvenile resistance and susceptibility loci in Biomphalaria glabrata. Int. J. Parasitol. 43, 669-677.

King, C.H., Bertsch, D., 2015. Historical perspective: snail control to prevent schistosomiasis. PLoS Negl. Trop. Dis. 9 e0003657.

King, C.H., Olbrych, S.K., Soon, M., Singer, M.E., Carter, J., Colley, D.G., 2011. Utility of repeated praziquantel dosing in the treatment of schistosomiasis in high-risk communities in Africa: a systematic review. PLoS Negl. Trop. Dis. 5 e1321.
Knight, M., Arican-Goktas, H.D., Ittiprasert, W., Odoemelam, E.C., Miller, A.N. Bridger, J.M., 2014. Schistosomes and snails: a molecular encounter. Front. Genet. 5, 230.

Knight, M., Elhelu, O., Smith, M., Miller, A., Raghavan, N., Wellman, C., Cousin, C., Dixon, F., Mann, V., Rinaldi, G., Ittiprasert, W., Brindley, P., 2015. Susceptibility of snails to infection with schistosomes in influenced by temperature and expression of heat shock proteins. Epidemiology 5, 1000189.

Knight, M., Ittiprasert, W., Odoemelam, E.C., Adema, C.M., Miller, A., Raghavan, N., Bridger, J.M., 2011. Non-random organization of the Biomphalaria glabrata genome in interphase Bge cells and the spatial repositioning of activated genes in cells co-cultured with Schistosoma mansoni. Int. J. Parasitol. 41, 61-70.

Knight, M., Miller, A.N., Patterson, C.N., Rowe, C.G., Michaels, G., Carr, D., Richards, C. S., Lewis, F.A., 1999. The identification of markers segregating with resistance to Schistosoma mansoni infection in the snail Biomphalaria glabrata. Proc. Natl. Acad. Sci. U.S.A. 96, 1510-1515.

Kosak, S.T., Groudine, M., 2004a. Form follows function: the genomic organization of cellular differentiation. Genes Dev. 18, 1371-1384.

Kosak, S.T., Groudine, M., 2004b. Gene order and dynamic domains. Science 306 644-647.

Lampel, S., Bridger, J.M., Zirbel, R.M., Mathieu, U.R., Lichter, P., 1997. Nuclear RNA accumulations contain released transcripts and exhibit specific distributions with respect to Sm antigen foci. DNA Cell Biol. 16, 1133-1142.

Lelo, A.E., Mburu, D.N., Magoma, G.N., Mungai, B.N., Kihara, J.H., Mwangi, I.N. Maina, G.M., Kinuthia, J.M., Mutuku, M.W., Loker, E.S., Mkoji, G.M., Steinauer, M L., 2014. No apparent reduction in schistosome burden or genetic diversity following four years of school-based mass drug administration in mwea, central kenya, a heavy transmission area. PLoS Negl. Trop. Dis. 8 e3221.

Li, L.Y., Sun, X.K., Zhao, Q., Zhang, L.J., Li, Q.W., Wang, L.L., Gao, H., 2010. Gene mapping of developmental dysplasia of the hip in chromosome $17 \mathrm{q} 21$ region. Zhonghua Yi Xue Yi Chuan Xue Za Zhi 27, 620-625.

Mali, P., Esvelt, K.M., Church, G.M., 2013. Cas9 as a versatile tool for engineering biology. Nat. Methods 10, 957-963.

Marques, D.P., Rosa, F.M., Maciel, E., Negrao-Correa, D., Teles, H.M., Caldeira, R.L., Jannotti-Passos, L.K., Coelho, P.M., 2014. Reduced susceptibility of a Biomphalaria tenagophila population to Schistosoma mansoni after introducing the resistant Taim/RS strain of $B$. tenagophila into Herivelton Martins stream. PLoS One 9 e99573.

Mutuku, M.W., Dweni, C.K., Mwangi, M., Kinuthia, J.M., Mwangi, I.N., Maina, G.M. Agola, L.E., Zhang, S.M., Maranga, R., Loker, E.S., Mkoji, G.M., 2014. Field-derived Schistosoma mansoni and Biomphalaria pfeifferi in Kenya: a compatible association characterized by lack of strong local adaptation, and presence of some snails able to persistently produce cercariae for over a year. Parasites Vectors 7, 533.

Odoemelam, E., Raghavan, N., Miller, A., Bridger, J.M., Knight, M., 2009. Revised karyotyping and gene mapping of the Biomphalaria glabrata embryonic (Bge) cell line. Int. J. Parasitol. 39, 675-681.

Pennisi, E., 2013. The CRISPR craze. Science 341, 833-836.

Perrin, C., Lepesant, J.M., Roger, E., Duval, D., Fneich, S., Thuillier, V., Alliene, J.F., Mitta, G., Grunau, C., Cosseau, C., 2013. Schistosoma mansoni mucin gene (SmPoMuc) expression: epigenetic control to shape adaptation to a new host PLoS Pathog. 9 e1003571.

Perry, K.J., Henry, J.Q., 2015. CRISPR/Cas9-mediated genome modification in the mollusc, Crepidula fornicata. Genesis 53, 237-244.

Pointier, J.P., 1993. The introduction of Melanoides tuberculata (Mollusca: Thiaridae) to the island of Saint Lucia (West Indies) and its role in the decline of Biomphalaria glabrata, the snail intermediate host of Schistosoma mansoni. Acta Trop. 54, 13-18.

Richards, C.S., Shade, P.C., 1987. The genetic variation of compatibility in Biomphalaria glabrata and Schistosoma mansoni. J. Parasitol. 73, 1146-1151.

Roquis, D., Lepesant, J.M., Picard, M.A., Freitag, M., Parrinello, H., Groth, M., Emans R., Cosseau, C., Grunau, C., 2015. The epigenome of Schistosoma manson provides insight about how cercariae poise transcription until infection. PLoS Negl. Trop. Dis. 9 e0003853.

Saint-Carlier, E., Riviere, G., 2015. Regulation of Hox orthologues in the oyster Crassostrea gigas evidences a functional role for promoter DNA methylation in an invertebrate. FEBS Lett. 589, 1459-1466.

Sexton, T., Schober, H., Fraser, P., Gasser, S.M., 2007. Gene regulation through nuclear organization. Nat. Struct. Mol. Biol. 14, 1049-1055.

Sokolow, S.H., Huttinger, E., Jouanard, N., Hsieh, M.H., Lafferty, K.D., Kuris, A.M., Riveau, G., Senghor, S., Thiam, C., N'Diaye, A., Faye, D.S., De Leo, G.A., 2015. Reduced transmission of human schistosomiasis after restoration of a native river prawn that preys on the snail intermediate host. Proc. Natl. Acad. Sci. U.S. A. $112,9650-9655$.

Szczerbal, I., Bridger, J.M., 2010. Association of adipogenic genes with SC-35 domains during porcine adipogenesis. Chromosome Res. 18, 887-895.

Szczerbal, I., Foster, H.A., Bridger, J.M., 2009. The spatial repositioning of adipogenesis genes is correlated with their expression status in a porcine mesenchymal stem cell adipogenesis model system. Chromosoma 118, 647663.

Yoshino, T.P., Brown, M., Wu, X.J., Jackson, C.J., Ocadiz-Ruiz, R., Chalmers, I.W., Kolb, M., Hokke, C.H., Hoffmann, K.F., 2014. Excreted/secreted Schistosoma manson venom allergen-like 9 (SmVAL9) modulates host extracellular matrix remodelling gene expression. Int. J. Parasitol. 44, 551-563. 